Article

\title{
Thermal Cyclic Properties of Ti-Pd-Pt-Zr High-Temperature Shape Memory Alloys
}

\author{
Wataru Tasaki ${ }^{1,2,3}$, Masayuki Shimojo ${ }^{2}$ (D) and Yoko Yamabe-Mitarai ${ }^{1, *}$ \\ 1 National Institute for Materials Science (NIMS), Tsukuba, Ibaraki 305-0047, Japan; tasaki.wataru@nims.go.jp \\ 2 Department of Materials Science and Engineering, Shibaura Institute of Technology, Koto, \\ Tokyo 135-8548, Japan; mshimojo@shibaura-it.ac.jp \\ 3 Japan Society for the Promotion of Science, Chiyoda, Tokyo 102-0083, Japan \\ * Correspondence: mitarai.yoko@nims.go.jp
}

Received: 22 October 2019; Accepted: 12 November 2019; Published: 14 November 2019

check for updates

\begin{abstract}
In this study, the thermal cyclic properties of Ti-(50-x)Pd-xPt-5Zr alloys ( $x=5,15,25$, at $\%$ ), comprising B2 and B19 structures in austenite and martensite, were investigated by a thermal cyclic compression test under a constant load of between 15 and $200 \mathrm{MPa}$. The transformation temperature measured using differential scanning calorimetry increased with increasing $\mathrm{Pt}$ concentration. The highest austenite finishing $\left(A_{\mathrm{f}}\right)$ temperature, $648{ }^{\circ} \mathrm{C}$, was obtained in the Ti-25Pd-25Pt-5Zr alloy. Irrecoverable strain due to thermal cyclic testing was observed during each test, even at a stress of $50 \mathrm{MPa}$. The work output, calculated as the product of the transformation strain and the applied stress from strain-temperature curves, decreased with increasing Pt concentration. This was because of the lower strength of the austenite phase due to $A_{\mathrm{f}}$ increasing with an increase in the concentration of Pt. Although irrecoverable strain was observed with the first thermal cycle test, it decreased after several thermal cyclic tests, which are called training.
\end{abstract}

Keywords: shape memory alloys; titanium palladium; thermal cyclic properties; training

\section{Introduction}

Shape memory alloys (SMAs) are useful materials for actuators. Specifically, Ti-Ni-based SMAs are currently used in temperature-sensitive devices [1]. SMAs are expected to be used at high temperatures, i.e., $200-800^{\circ} \mathrm{C}$, in automotive and aerospace applications to increase the thermal efficiency of engines [2]. The operating temperature of an SMA is related to its martensite transformation temperature (MTT). The highest MTT of Ti-Ni is approximately $60^{\circ} \mathrm{C}$ [3], which is insufficiently high for applications greater than $200{ }^{\circ} \mathrm{C}$.

Numerous efforts had been made to raise the MTT by adding alloying elements to Ti-Ni, such as $\mathrm{Hf}, \mathrm{Zr}, \mathrm{Pd}, \mathrm{Pt}$, and $\mathrm{Au}$; these are reviewed in [2]. Recently, the high-temperature $\mathrm{SMA}, \mathrm{Ni}_{50.3} \mathrm{Ti}_{29.7} \mathrm{Hf}_{20}$, has received a lot of attention; it is strengthened by nano-sized precipitates called "H phase" $[4,5]$, and a perfect shape recovery was successfully obtained, even under 500-700 MPa. The austenite finishing temperature $A_{\mathrm{f}}$ of $\mathrm{Ni}_{50.3} \mathrm{Ti}_{29.7} \mathrm{Hf}_{20}$ is typically $166^{\circ} \mathrm{C}$ under unloading conditions, but this rises to $300^{\circ} \mathrm{C}$ under loading conditions. Furthermore, the strength at $250{ }^{\circ} \mathrm{C}$ and the work output are approximately $800 \mathrm{MPa}$ and $20 \mathrm{~J} / \mathrm{cm}^{3}$ [6-10]. Even so, the MTT of $\mathrm{Ni}_{50.3} \mathrm{Ti}_{29.7} \mathrm{Hf}_{20}$ remains below $300{ }^{\circ} \mathrm{C}$. To increase the MTT, another attempt is necessary.

Ti-Ta-based $\beta$-Ti alloys have also been investigated as potential high-temperature SMAs [11]. A stable shape recovery was obtained between 100 and $200{ }^{\circ} \mathrm{C}$ in Ti-32 at $\%$ Ta.

Thus, in our previous study, we focused on Ti-Pd, Ti-Au, and Ti-Pt because they exhibit an MT from a B2 to a B19 structure, and their MTT is greater than $500{ }^{\circ} \mathrm{C}[12,13]$. However, one problem of binary compounds is their low strength in the austenite phase, which results in a poor shape 
memory effect [14-16]. To increase the high-temperature strength of Ti-Pd [17,18], Ti-Au [19,20], and Ti-Pt [21-25], the addition of alloying elements has been attempted; this process is reviewed in [26-28]. It was found that an alloying element has some effect at improving the strength of the austenite and martensite phases, resulting in improved shape recovery. However, in most cases, the MTT decreases when alloying elements are added.

In our previous study, $\mathrm{Zr}$ and $\mathrm{Pd}$ were simultaneously added to Ti-Pt to improve shape recovery and control MTT [29]. The concentration of $\mathrm{Zr}$ was limited to 5 at $\%$, and $\mathrm{Pt}$ was replaced by $\mathrm{Pd}$ in a concentration range of between 5 and 15 at $\%$. The MTT, $A_{\mathrm{f}}, A_{\mathrm{s}}$ (austenite start temperature), $M_{\mathrm{S}}$ (martensite start temperature), and $M_{\mathrm{f}}$ (martensite finishing temperature) of Ti-35Pt-15Pd-5Zr decreased to $804,725,713$, and $590^{\circ} \mathrm{C}$ from $1066,1047,1025$, and $1012{ }^{\circ} \mathrm{C}$ for Ti-50Pt, and 985,939 , 897 , and $840{ }^{\circ} \mathrm{C}$ for Ti-50Pt-5Zr. However, the MTT of Ti-35Pt-15Pd-5Zr remained over $590{ }^{\circ} \mathrm{C}$. The large irrecoverable strain observed in Ti-50Pt and Ti-50Pt-5Zr was drastically decreased by adding 15 at $\% \mathrm{Pd}$, but it was not removed completely. In this study, further addition of Pd to TiPt-5Zr. (i.e., the addition of Pt to Ti-50Pd-5Zr) was attempted. The effect of Pt addition to Ti-50Pd-5Zr on the MTT and shape recovery was investigated.

\section{Experimental Procedure}

Ingots totaling $18 \mathrm{~g}$ with nominal compositions of Ti-45Pd-5Pt-5Zr, Ti-35Pd-15Pt-5Zt, and Ti-25Pd-25Pt-5Zr (at\%) were prepared by arc melting in an Ar atmosphere. The purity of elements used for the ingots was $99.5 \%$ for Ti, 99.99\% for Pd and $\mathrm{Pt}$, and $99.7 \%$ for $\mathrm{Zr}$. The alloy ingots were sealed in silica tubes with Ar gas and solution-treated at $1000^{\circ} \mathrm{C}$ for $3 \mathrm{~h}$, followed by quenching in iced water. An ingot of Ti-50Pd-5Zr was also prepared as a reference using the same solution treatment to investigate the shape recovery behavior described in the following paragraph.

The microstructures of the solution-treated samples were observed using scanning electron microscopy (SEM) (JEOL 7001F, JEOL, Tokyo, Japan) at an accelerating voltage of $20 \mathrm{kV}$. The samples were etched using nitrohydrochloric acid after being polished for observation. A phase composition analysis was performed using a field emission electron probe microanalyzer (JSM-6500F, JEOL, Tokyo, Japan) at $15 \mathrm{kV}$ and $5 \times 10^{-8} \mathrm{~A}$. A LIF was used as an analyzing crystal for Ti and $\mathrm{Zr}$, while a PET was for Pt and Pd.

X-ray diffraction (RINT-TTR III, Rigaku Co., Tokyo, Japan) measurements were conducted for solution-treated samples at room temperature and at $700{ }^{\circ} \mathrm{C}$ using $\mathrm{CuK} \alpha$ radiation at $50 \mathrm{kV}$ and $300 \mathrm{~mA}$.

Specimens of $4 \mathrm{~mm}$ in diameter and $1 \mathrm{~mm}$ in height were cut for differential scanning calorimetry (DSC) (DSC3200, NETZSH Japan K.K. Yokohama, Japan) to measure the MTT. The heating and cooling rates were both $10^{\circ} \mathrm{C} / \mathrm{min}$.

Specimens of $3 \times 3 \times 5 \mathrm{~mm}$ were cut for thermal cyclic compression tests (Shimadzu AG-X, Shimadzu) to evaluate their shape recovery and work output. A thermocouple was welded on the specimen to measure its temperature. Specimens were heated to $30^{\circ} \mathrm{C}$ above $A_{\mathrm{f}}$ by induction heating, and then cooled to a temperature lower than $M_{\mathrm{f}}$ under a constant load of between 15 and $200 \mathrm{MPa}$. Five thermal cycles under 15, 50, 100, 150, and $200 \mathrm{MPa}$ were applied for the same samples (in the order given). The heating and cooling rates were both $50^{\circ} \mathrm{C} / \mathrm{min}$. The work output (work per volume) was obtained from the product of recovery strain and applied stress.

The strengths of the austenite and martensite phases were investigated through compression tests for the $3 \times 3 \times 5 \mathrm{~mm}$ specimens. The compression tests were performed at $M_{\mathrm{f}}-30$ and $A_{\mathrm{f}}+30^{\circ} \mathrm{C}$ using $3 \times 10^{-3} / \mathrm{s}$ as a strain rate.

The martensite variants of the solution-treated and thermally-cycled samples were observed using a TSL electron backscattered diffraction (EBSD) detector attached to the SEM (JEOL 7001F, JEOL) at an accelerating voltage of $25 \mathrm{kV}$. Post-processing data analyses using the B19 structures of Ti-Pd, whose lattice parameters are $\mathrm{a}=0.456 \mathrm{~nm}, \mathrm{~b}=0.281 \mathrm{~nm}$, and $\mathrm{c}=0.489 \mathrm{~nm}$, respectively, were conducted in the TSL-orientation imaging microscopy V 7.0 software (TSL solutions, Sagamihara, Japan). 


\section{Results and Discussion}

\subsection{Martensite Transformation Temperature}

The XRD patterns of Ti-Pd-Pt-Zr at room temperature and at $700{ }^{\circ} \mathrm{C}$ are plotted in Figure 1. The B19 and B2 structures were identified for all the tested alloys at room temperature and at $700{ }^{\circ} \mathrm{C}$, respectively, as with Ti-50Pd-5Zr [17], indicating that the MT from the B2 to B19 structures occurred in Ti-Pd-Pt-Zr.
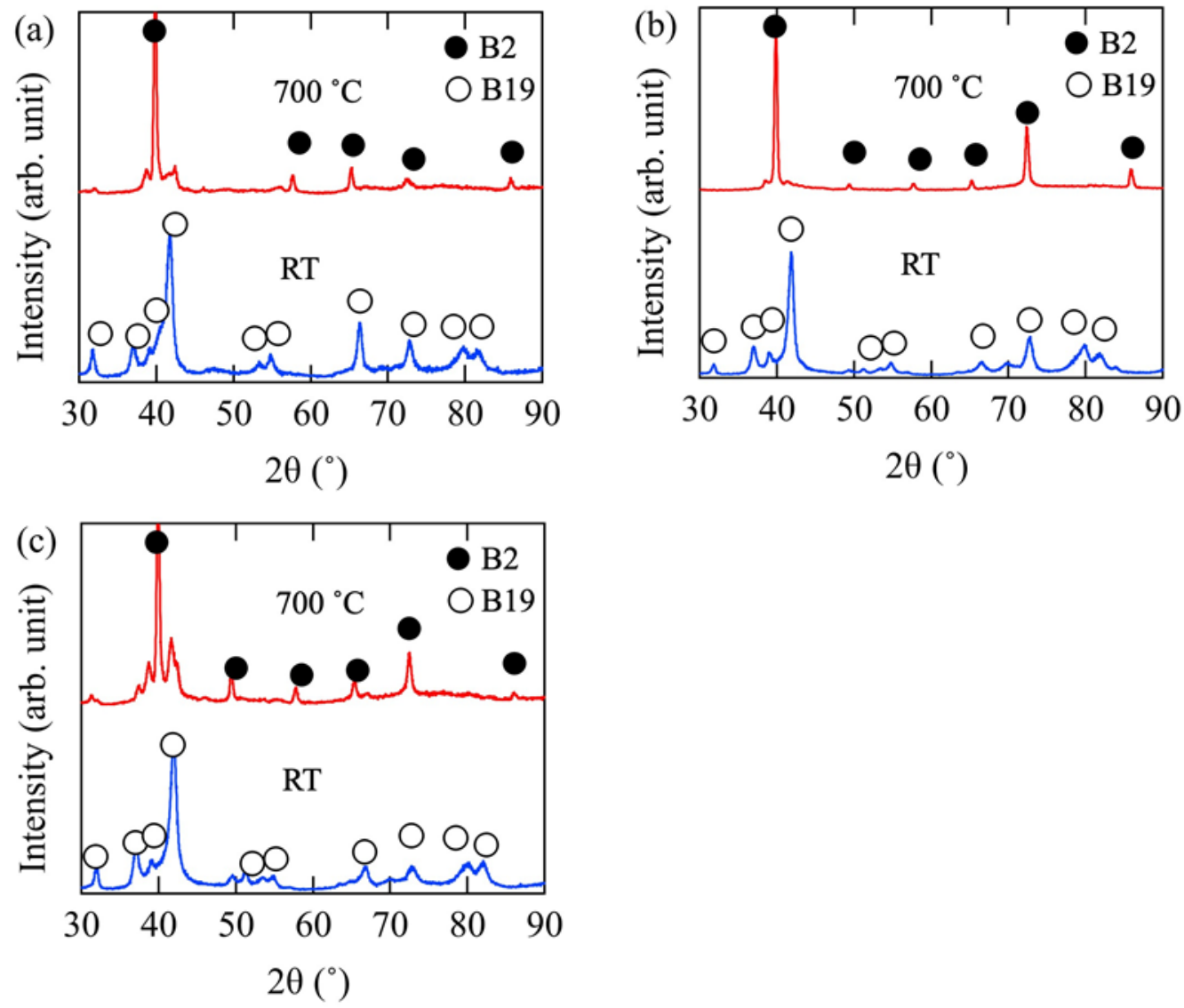

Figure 1. XRD patterns of (a) Ti-45Pd-5Pt-5Zr, (b) Ti-35Pd-15Pt-5Zt, and (c) Ti-25Pd-25Pt-5Zr measured at room temperature and $700{ }^{\circ} \mathrm{C}$.

To measure the MTT, a DSC analysis was performed for Ti-Pd-Pt-Zr. Sharp peaks of endothermic and exothermic reactions were clearly observed, as with Ti-50Pd-5Zr [17], indicating the MT as given in Figure 2. The MTT increased with increasing Pt contents. The highest intensity of the DSC peaks was obtained in Ti-35Pd-15Pt-5Zr, and the DSC peaks broadened in Ti-25Pd-25Pt-5Zr. The MTT, $A_{\mathrm{s}}, A_{\mathrm{f}}$, $M_{\mathrm{s}}$, and $M_{\mathrm{f}}$, as measured by DSC, are summarized in Table 1, together with temperature hysteresis between $A_{\mathrm{f}}$ and $M_{\mathrm{s}}$. The MTTs of Ti-50Pd-5Zr are also shown in Table 1 [28]. The changes in MTT with Pt contents are plotted together with those of Ti-50Pd-5Zr [28] and Pt-rich Ti-Pd-Pt-Zr [29] in Figure 3. The MTT gradually increased with increasing the Pt content. The transformation enthalpies of Ti-Pd-Pt-Zr estimated from the DSC curves in Figure 2 were approximately $-2800 \mathrm{~J} / \mathrm{mol}$, and there was no clear difference among the tested alloys, although there is trend of slightly increasing enthalpy with an increase in the content of Pt. It is reported that the enthalpy of Ti-50.3at\% $\%$ is $-1819 \mathrm{~J} / \mathrm{mol}$ [30]. The enthalpy of Ti-Pd-Pt-Zr was larger than that of Ti-Ni. 

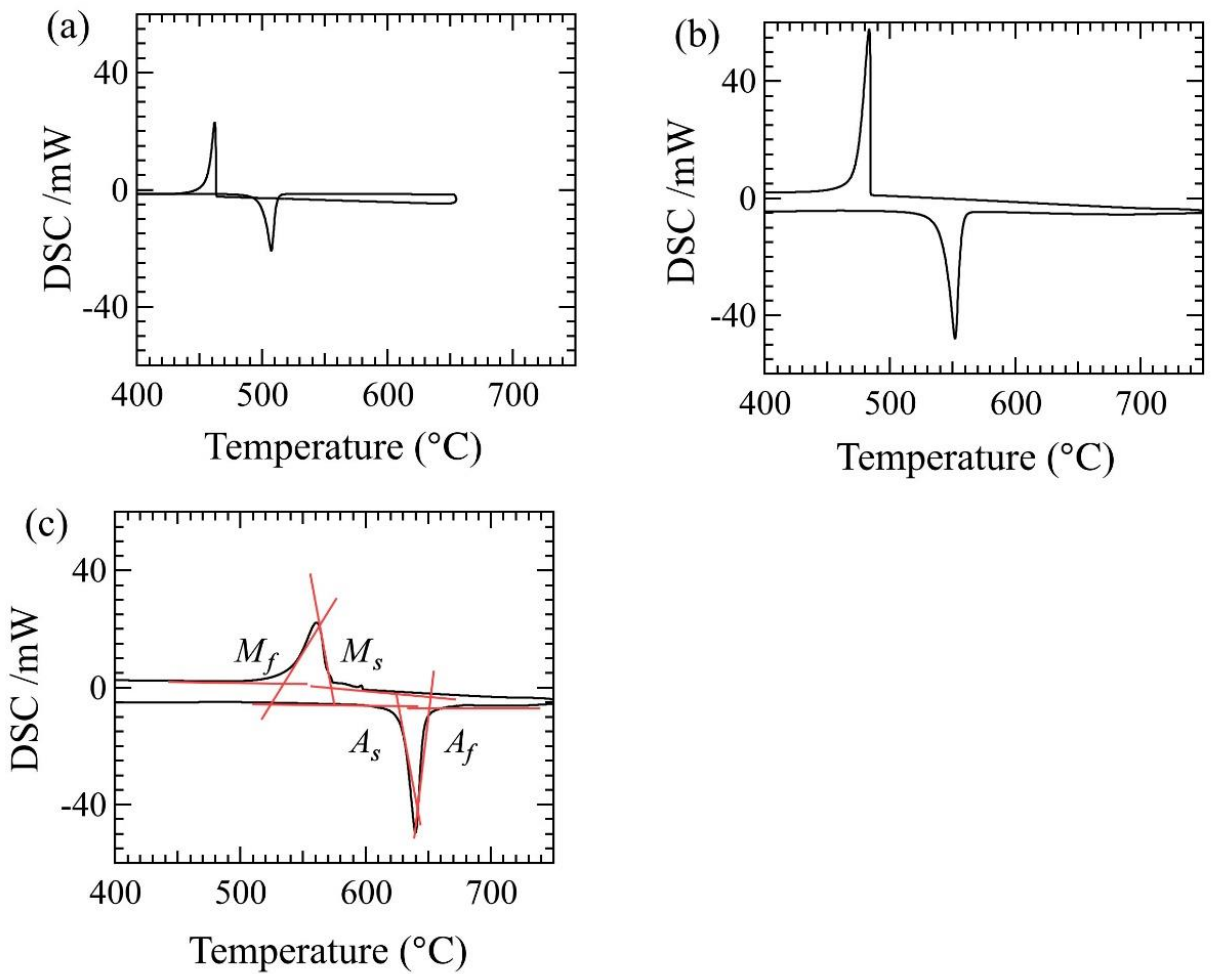

Figure 2. DSC curves of (a) Ti-45Pd-5Pt-5Zr, (b) Ti-35Pd-15Pt-5Zt, and (c) Ti-25Pd-25Pt-5Zr.

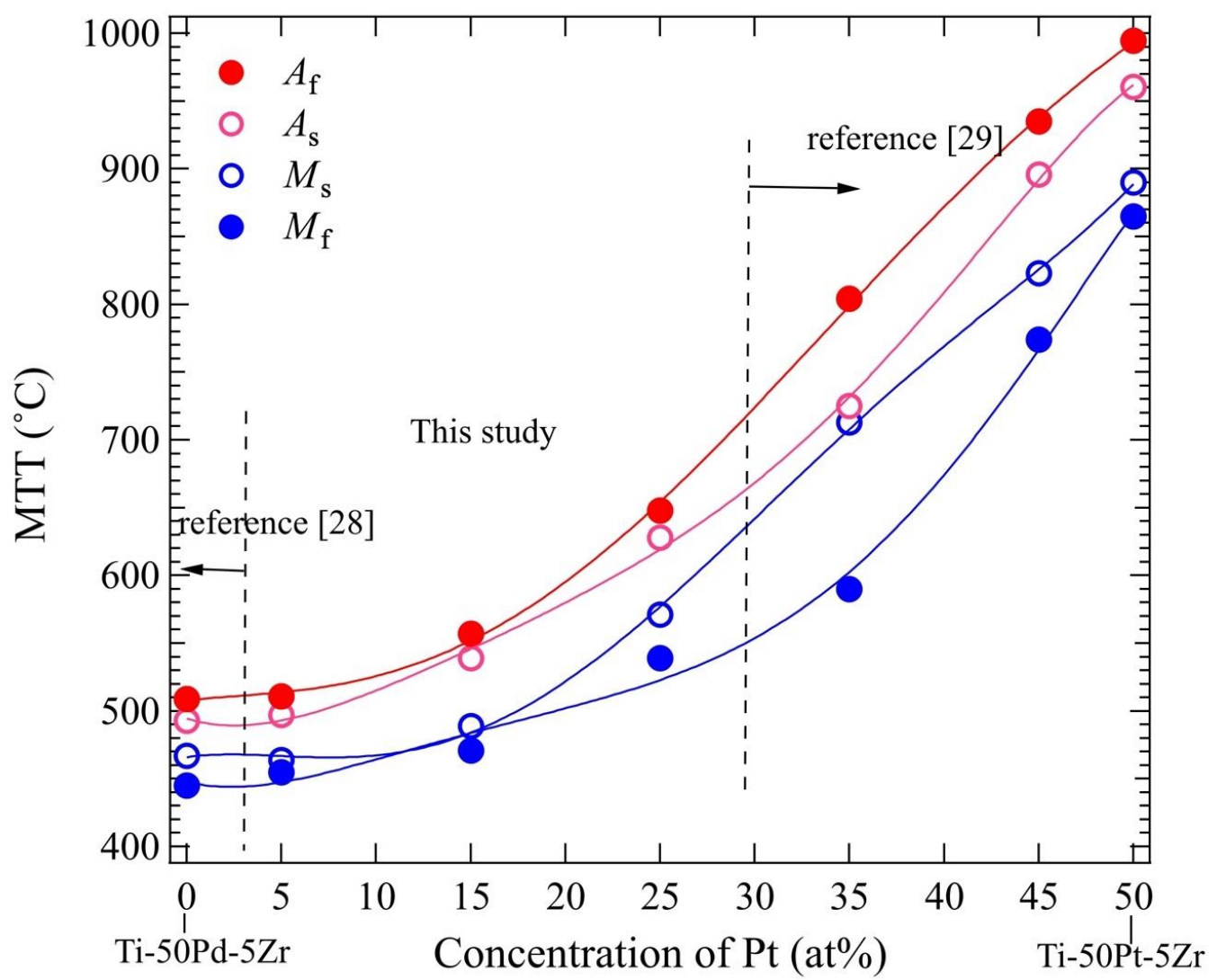

Figure 3. Martensite start $\left(M_{\mathrm{s}}\right)$, martensite finishing $\left(M_{\mathrm{f}}\right)$, austenite start $\left(A_{\mathrm{s}}\right)$, and austenite finishing $\left(A_{\mathrm{f}}\right)$ temperatures as a function of the concentration of $\mathrm{Pt}$. 
Table 1. MT temperatures $\left({ }^{\circ} \mathrm{C}\right)$ and temperature hysteresis between Af and Ms of ternary Ti-Pd-Zr and quaternary Ti-Pd-Pt-Zr.

\begin{tabular}{cccccc}
\hline Alloy & $\boldsymbol{A}_{\mathbf{s}}$ & $\boldsymbol{A}_{\mathbf{f}}$ & $\boldsymbol{M}_{\mathbf{s}}$ & $\boldsymbol{M}_{\mathbf{f}}$ & Hysteresis $\left(\boldsymbol{A}_{\mathbf{f}}-\boldsymbol{M}_{\mathbf{s}}\right)$ \\
\hline Ti-50Pd-5Zr [28] & 484 & 503 & 457 & 439 & 46 \\
Ti-45Pd-5Pt-5Zr & 497 & 511 & 464 & 455 & 47 \\
Ti-35Pd-15Pt-5Zr & 539 & 557 & 485 & 471 & 72 \\
Ti-25Pd-25Pt-5Zr & 628 & 648 & 571 & 539 & 77 \\
\hline
\end{tabular}

The temperature hysteresis between $A_{\mathrm{f}}$ and $M_{\mathrm{S}}$ is a critical property for SMAs, because it represents the temperature range that is necessary for shape recovery to occur. A smaller temperature hysteresis induces a faster response of SMAs. The temperature hysteresis of Ti-50Pd-5Zr and Ti-45Pd-5Pt-5Zr was approximately $50{ }^{\circ} \mathrm{C}$, i.e., less than that of TiPd at $56^{\circ} \mathrm{C}$ [28]. However, with further addition of $\mathrm{Pt}$, the temperature hysteresis increased to above $70^{\circ} \mathrm{C}$. Because the temperature hysteresis of Ti-Pt was $68^{\circ} \mathrm{C}$ [16] and greater than that of Ti-Pd, increasing temperature hysteresis by $\mathrm{Pt}$ addition is reasonable.

The microstructures of the heat-treated samples at $1000{ }^{\circ} \mathrm{C}$ for $168 \mathrm{~h}$ followed by ice water quenching were observed by SEM, and are shown in Figure 4 . The twin structure obtained by MT was observed in all of the tested Ti-Pd-Pt-Zr, as with Ti-50Pd-5Zr [17]. The results of microstructure observation, DSC measurement, and XRD measurement indicated that MT from the B2 to B19 structures occurred during cooling in Ti-Pd-Pt-Zr. Particles with dark contrast represented by arrows were observed in Ti-45Pd-5Pt-5Zr and Ti-35Pt-15Pt-5Zr, as shown in Figure 4a,b, respectively. The phase composition analysis by EPMA for Ti-Pd-Pt-Zr is presented in Table 2. The dark-contrast phase was identified as $\mathrm{Ti}_{2} \mathrm{Pd}$ in Ti-45Pd-5Pt-5Zr and Ti-35Pd-15Pt-5Zr because the composition ratio of $(\mathrm{Ti}+\mathrm{Zr}):(\mathrm{Pd}+\mathrm{Pt})$ was approximately 2:1, if we consider that $\mathrm{Zr}$ and $\mathrm{Pt}$ partitioned to the $\mathrm{Ti}$ and $\mathrm{Pd}$ sites, respectively. Precipitation of $\mathrm{Ti}_{2} \mathrm{Pd}$ was also observed in Ti-50Pd-5Zr [17]. In Ti-25Pt-25Pt-5Zr, dark- and bright-contrast phases were observed, as shown in Figure 4c (represented by arrows). The composition ratio of $(\mathrm{Ti}+\mathrm{Zr}):(\mathrm{Pd}+\mathrm{Pt})$ was approximately 3:1 and 5:3 for the dark- and bright-contrast phases, respectively. The dark-contrast phase included a higher amount of Pt compared to that in the dark-contrast phases observed in both Ti-45Pd-5Pt-5Zr and Ti-35Pd-15Pt-5Zr. It was then considered that the dark and bright phases were $\mathrm{Ti}_{3} \mathrm{Pt}$ and $\mathrm{Ti}_{4} \mathrm{Pt}_{3}$, respectively. These second and third phases were not detected in XRD patterns because of the small volume fraction. 

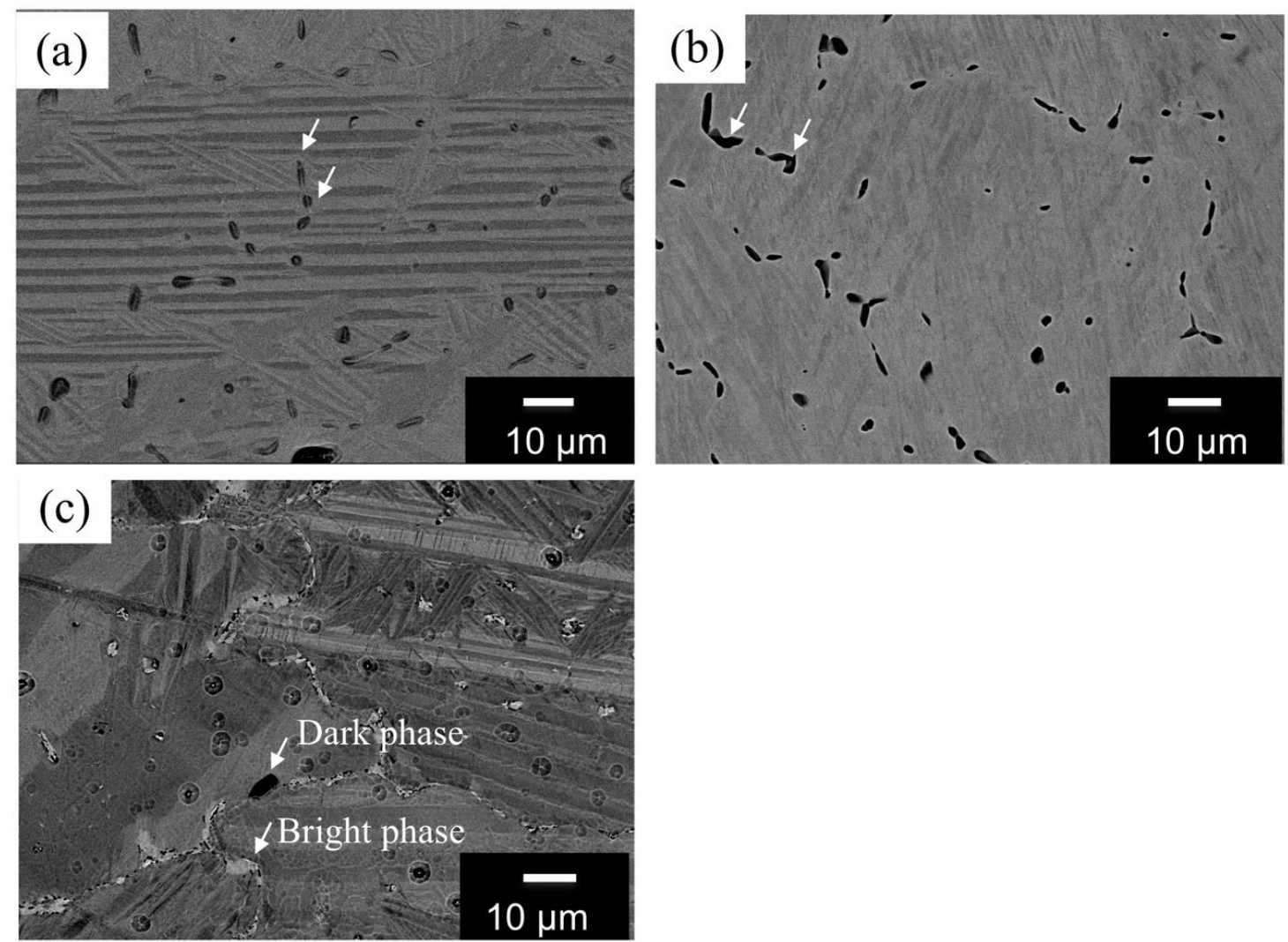

Figure 4. Backscattered images of (a) Ti-45Pd-5Pt-5Zr, (b) Ti-35Pd-15Pt-5Zr, and (c) Ti-25Pd-25Pt-5Zr.

Table 2. Composition of precipitates in Ti-Pd-Pt-Zr.

\begin{tabular}{ccccc}
\hline Alloy & Ti (at\%) & Zr (at\%) & Pd (at\%) & Pt (at \%) \\
\hline Ti-45Pd-5Pt-5Zr: $\mathrm{Ti}_{2} \mathrm{Pd}$ & 62.2 & 5.3 & 26.3 & 6.2 \\
Ti-35Pd-15Pt-5Zr: $\mathrm{Ti}_{2} \mathrm{Pd}$ & 60.6 & 7.0 & 21.3 & 11.1 \\
Ti-25Pd-25Pt-5Zr (dark): $\mathrm{Ti}_{3} \mathrm{Pt}$ & 67.7 & 1.7 & 8.6 & 22.0 \\
Ti-25Pd-25Pt-5Zr (Bright): $\mathrm{Ti}_{4} \mathrm{Pt}_{3}$ & 46.9 & 17.0 & 4.5 & 31.6 \\
\hline
\end{tabular}

\subsection{Thermal Cyclic Properties}

A thermal cycle test was performed under a constant stress of between 15 and $200 \mathrm{MPa}$ to investigate the shape memory property. First, a sample was placed in the testing machine and $15 \mathrm{MPa}$ was applied in compression mode. Then, the sample was heated to $A_{\mathrm{f}}+30^{\circ} \mathrm{C}$ and cooled to room temperature or $M_{\mathrm{f}}-30{ }^{\circ} \mathrm{C}$, and again heated to $A_{\mathrm{f}}+30^{\circ} \mathrm{C}$. After the first thermal cycle, the applied stress was increased to $50 \mathrm{MPa}$, and the second cycle test was performed. The applied stress was increased to 100, 150, and $200 \mathrm{MPa}$. Five thermal cycles were applied in total for the same samples.

The strain-temperature curves shown in Figure 5 indicate the shape memory properties of the alloys. Shape recovery was obtained approximately above $400{ }^{\circ} \mathrm{C}$, although an irrecoverable strain was also observed. The starting temperature of shape recovery increased with an increase in $\mathrm{Pt}$ contents. The shape recovery started at approximately $500{ }^{\circ} \mathrm{C}$ in Ti-25Pd-25Pt-5Zr. Irrecoverable strain was not visible under $15 \mathrm{MPa}$ in any alloy. However, when the applied stress was increased to $50 \mathrm{MPa}$ and more, an irrecoverable strain appeared and increased with an increase in the applied stress. The transformation and recovery strains were also increased with an increase in the applied stress. This was because the deformation strain increasing with the increase in applied stress was recovered by reverse phase transformation. 

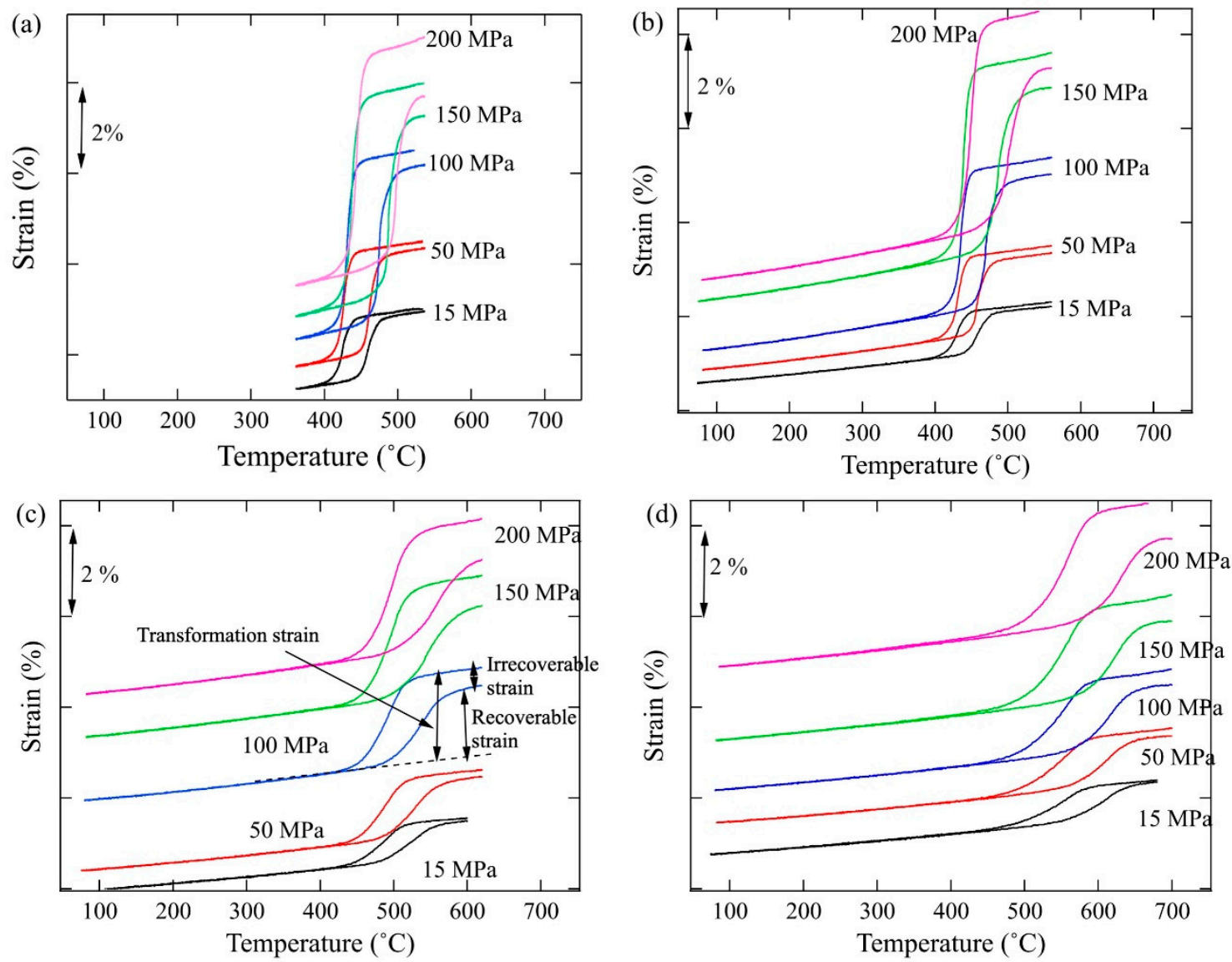

Figure 5. Strain-temperature curves of thermal cycle tests of between 15 and $200 \mathrm{MPa}$ for (a) Ti-50Pd-5Zr, (b) Ti-45Pd-5Pt-5Zr, (c) Ti-35Pd-15Pt-5Zr, and (d) Ti-25Pd-25Pt-5Zr.

In Figure 6, the recoverable, irrecoverable strain, work output, and recovery ratio obtained from Figure 5 are plotted together with the Pt-rich SMAs studied previously [28]. It is clear that the recoverable strain decreased drastically with an increase in Pt contents and a decrease in the applied stress. Although the irrecoverable strain was constant up to $35 \mathrm{at} \% \mathrm{Pt}$, it started to increase when $\mathrm{Pt}$ contents were greater than 35 at \%. As shown in Figure 5, the irrecoverable strain also increased with an increase in applied stress. It can be reasonably assumed that the large plastic strain was introduced under a large applied stress. The transformation strain is the sum of recoverable and irrecoverable strains. Because the irrecoverable strain was nearly the same value and the recoverable strain decreased with increasing Pt content up to $25 \mathrm{at} \% \mathrm{Pt}$, the transformation strain of Ti-Pd-Pt-Zr alloys decreased with an increase in Pt. The work output also decreased with increasing Pt content, but increased with an increase in the applied stress because the work output was obtained by the product of the recoverable strain and applied stress. The recovery ratio decreased with increasing $\mathrm{Pt}$ and applied stress. A drastic decrease in the recovery ratio was observed above $25 \mathrm{at} \% \mathrm{Pt}$. This indicates that the potential of alloys with $\mathrm{Pt}$ contents greater than 25 at $\%$ for high-temperature SMAs is very low. 

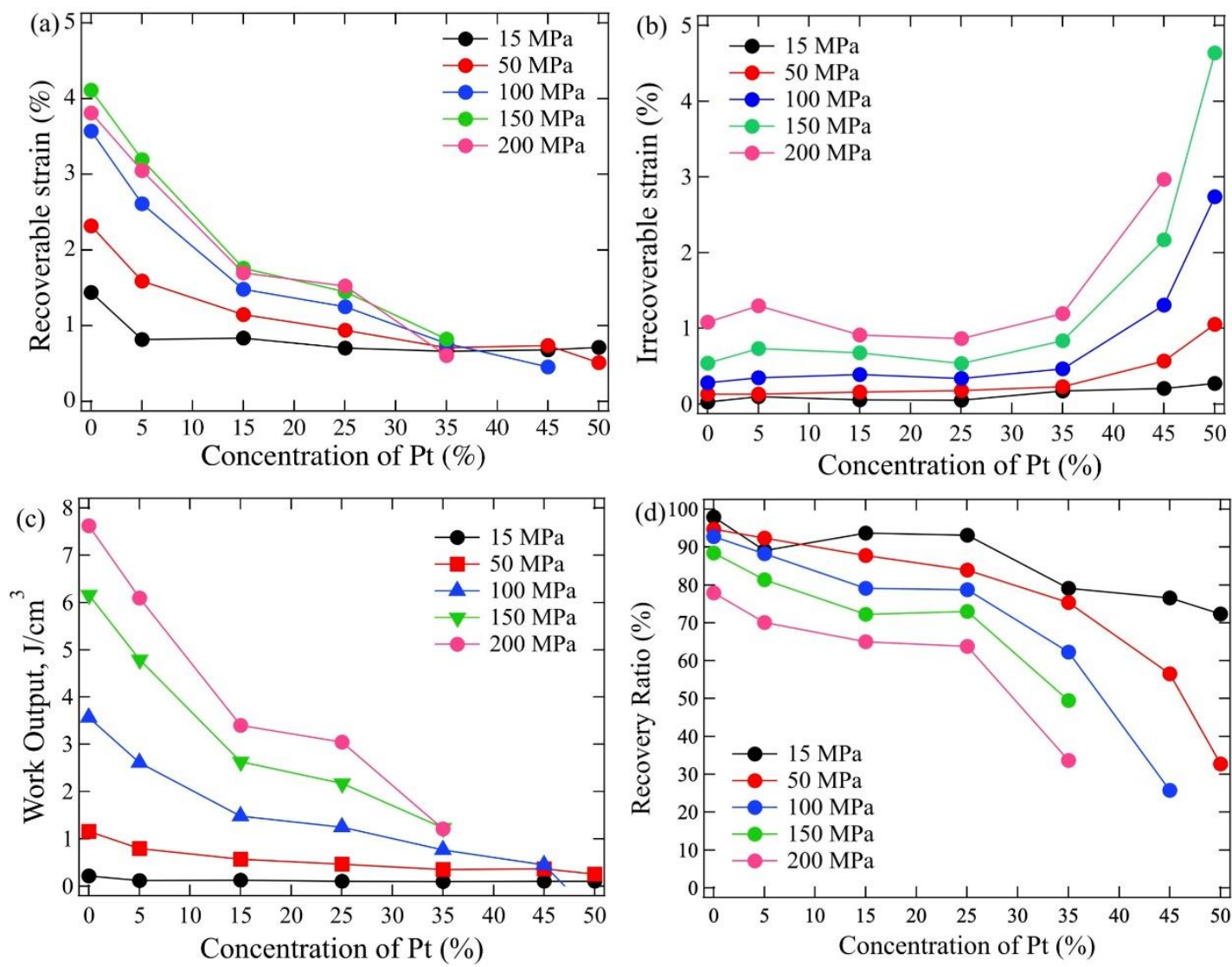

Figure 6. Changes in (a) recoverable strain, (b) irrecoverable strain, (c) work output, and (d) recovery ratio as a function of the number of cycles derived from the strain-temperature curves shown in Figure 5 .

To investigate an effect of the strength on the shape recovery effect, the Vickers hardness and $0.2 \%$ proof stress of martensite and austenite phases were measured. Table 3 and Figure 7 show the Vickers hardness of the martensite phase at room temperature and the $0.2 \%$ proof stress of the austenite phase together with Pt-rich Ti-Pd-Pt-Zr alloys [28]. The left- and right-side plots shown in Figure 7a represent the hardness and $0.2 \%$ proof stress of the martensite and austenite phases of Ti-50Pd-5Zr and Ti-50Pt-5Zr, respectively. The Vickers hardness at room temperature increased with an increase in $\mathrm{Pt}$ content because the hardness of Ti-50Pt-5Zr [24,29] was greater than that of Ti-50Pd-5Zr. The $0.2 \%$ proof stress and detwinning stress of the martensite phase also increased with increasing Pt content, even though no data for the $0.2 \%$ proof stress in Pt-rich Ti-Pd-Pt-Zr were available. However, the $0.2 \%$ proof stress of the austenite was nearly the same value at up to $15 \mathrm{at} \% \mathrm{Pt}$, but decreased with increasing Pt content above 25 at $\%$ Pt. Figure $7 \mathrm{~b}$ plots the $0.2 \%$ proof stress of the martensite and austenite phases as a function of the testing temperature. It can be reasonably assumed that a decrease in the $0.2 \%$ proof stress of the austenite phase above 25 at $\%$ Pt caused a drastic increase in $A_{\mathrm{f}}$ above $600{ }^{\circ} \mathrm{C}$ from $557{ }^{\circ} \mathrm{C}$ in Ti-35Pd-15Pt-5Zr, as shown in Figure 3. However, the $0.2 \%$ proof stress of the martensite increased, even with an increase in $M_{\mathrm{f}}$. Because the atomic size of $\mathrm{Pd}$ and $\mathrm{Pt}$ are nearly the same $(0.1375$ and $0.1387 \mathrm{~nm}$, respectively [31]), the solid-solution strengthening by Pt was considered not to be high. Thus, it is interesting that the proof stress of the martensite phase increased with the addition of $\mathrm{Pt}$, and even with an increase in the testing temperature. 

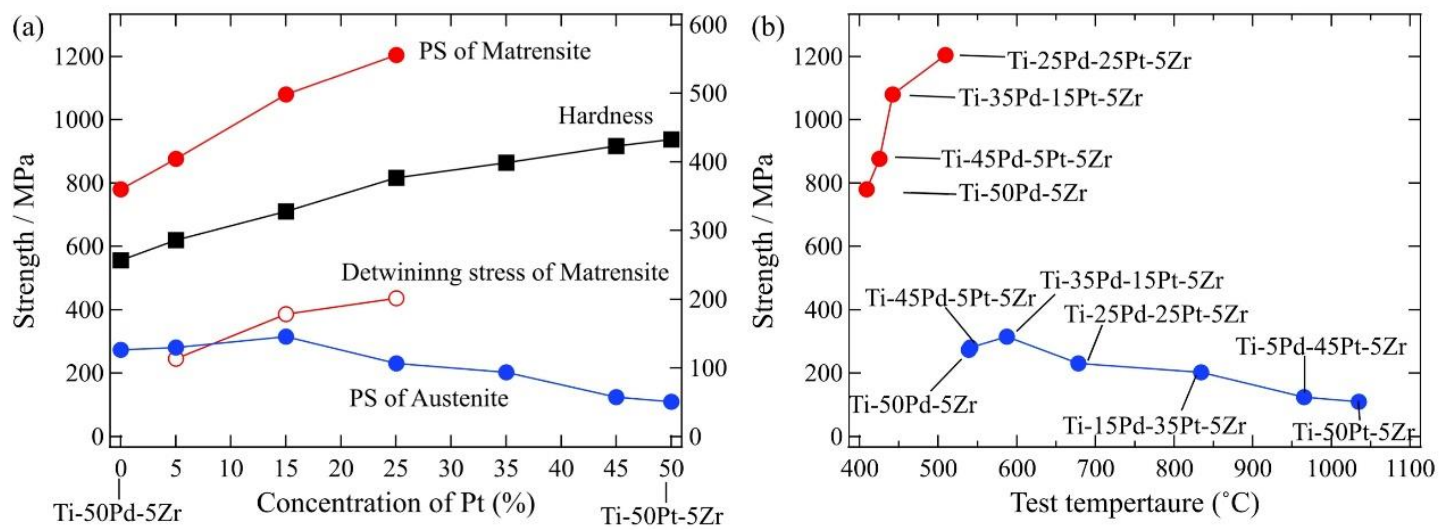

Figure 7. Vickers hardness at room temperature, $0.2 \%$ proof stress of the austenite and martensite phase, and detwinning stress of the martensite phase.

Table 3. Vickers hardness, $0.2 \%$ proof stress of the martensite and austenite phases, and detwinning stress of the martensite phase.

\begin{tabular}{ccccccc}
\hline \multirow{2}{*}{ Alloys } & \multicolumn{3}{c}{ Martensite Phase } & \multicolumn{2}{c}{ Austenite Phase } \\
\cline { 2 - 7 } & $\begin{array}{c}\text { Hardness at } \\
\text { Room } \\
\text { Temperature }\end{array}$ & $\begin{array}{c}\text { Test } \\
\text { Temperature } \\
\left({ }^{\circ} \mathbf{C}\right)\end{array}$ & $\begin{array}{c}\text { Proof } \\
\text { Stress, MPa }\end{array}$ & $\begin{array}{c}\text { Detwinning } \\
\text { Stress, MPa }\end{array}$ & $\begin{array}{c}\text { Detwinning } \\
\text { Stress, MPa }\end{array}$ & $\begin{array}{c}\text { Proof } \\
\text { Stress, MPa }\end{array}$ \\
\hline Ti-50Pd-5Zr & 357 & 409 & 780 & - & - & 274 \\
Ti-45Pd-5Pt-5Zr & 286 & 425 & 877 & 246 & 246 & 281 \\
Ti-35Pd-15Pt-5Zr & 328 & 442 & 1080 & 387 & 387 & 315 \\
Ti-25Pd-25Pt-5Zr & 377 & 509 & 1205 & 436 & 436 & 231 \\
Ti-15Pd-35Pt-5Zr [29] & 399 & - & - & - & - & 203 \\
Ti-5Pd-45Pt-5Zr [29] & 423 & - & - & - & - & 125 \\
Ti-50Pt-5Zr [24,29] & 433 & - & - & - & - & 110 \\
\hline
\end{tabular}

The drastic decrease in the strength of the austenite phase above $25 \mathrm{at} \% \mathrm{Pt}$ shown in Figure 7 may explain the increase of the irrecoverable strain shown in Figure 6b. Severe plastic deformation was considered to have occurred in the Pt-rich Ti-Pd-Pt-Zr alloys, resulting in a large extent of irrecoverable strain.

\subsection{Effects of Training}

It is known that repeated thermal cyclic tests, called "training", decreases irrecoverable strain, and a perfect recovery is finally obtained [32,32]. For example, the irrecoverable strain of Ti-Ni base alloys became almost 0 after 40 cycles under $80 \mathrm{MPa}$. The training was effective for Ti-Ni alloys strengthened by the addition of $\mathrm{Pd}$ or Sc. In addition, precipitation hardened by $\mathrm{Ti}(\mathrm{C}, \mathrm{O})$ and strengthened by dislocations processed by equal channel angular extrusion when the applied stress was increased.

In this study, two thermal cycle tests were performed for Ti-35Pd-15Pt-5Zr to investigate whether the initial stress or repetitive cycles was more effective at improving the shape memory effect. In the first test, the first cycle was performed at a different initial stress, and subsequent cycles were performed at a constant stress. In the second test, the cycles were performed at a different constant stress.

In the first test, the initial stress was changed to 100, 200, and $300 \mathrm{MPa}$ with different samples. The samples were then thermally cycled 10 times at $100 \mathrm{MPa}$. The strain-temperature curves for 10 cycles under $100 \mathrm{MPa}$ after the initial stress of 100, 200, and $300 \mathrm{MPa}$ are shown separately in Figure 8, where the first cycle is shown at the top. When the initial applied stress was $100 \mathrm{MPa}$, the following repetitive cycles at $100 \mathrm{MPa}$ were very stable, and the transformation and irrecoverable strains were nearly the same for all curves, as shown in Figure 8a. When the initial stress was 200 and $300 \mathrm{MPa}$, as shown in Figure 8b,c, the large recoverable and irrecoverable strains were observed in the first cycle. 
However, both transformation and irrecoverable strains decreased in the second cycles, and were stable in the subsequent cycles.
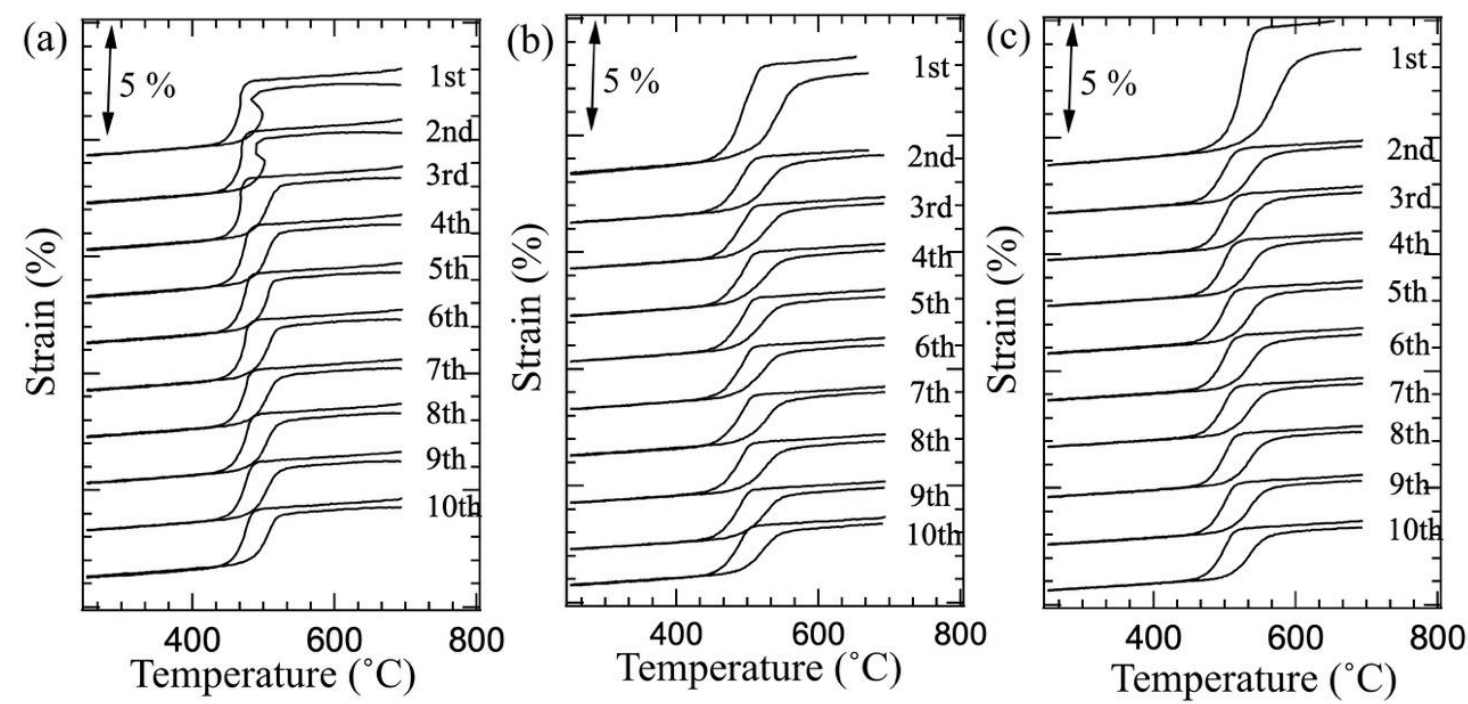

Figure 8. Strain-temperature curves of Ti-35Pd-15Pt-5Zr at $100 \mathrm{MPa}$ after application of initial stress of (a) $100 \mathrm{MPa}$, (b) $200 \mathrm{MPa}$, and (c) $300 \mathrm{MPa}$.

In Figure 9, the irrecoverable and recoverable strains and the work output under $100 \mathrm{MPa}$ obtained from Figure 8 are plotted with the number of cycles. The irrecoverable strain in the first cycle increased with an increase in the initial applied stress, but the strains were nearly the same in the subsequent cycles, as shown in Figure 9a. The recoverable strain under the condition of an initial applied stress of $100 \mathrm{MPa}$ was approximately $2.5 \%$, as shown in Figure $9 \mathrm{~b}$. However, the recoverable strain in the first cycle was nearly $4 \%$ when initial stresses of 200 and 300 MPa were applied, as shown in Figure 9b. The recoverable strain drastically decreased in the second cycle and was nearly the same for the sample, in which $100 \mathrm{MPa}$ was applied as the initial stress. Then, the recoverable strain gradually decreased with an increase in the number of cycles. This was because the high number of dislocations introduced during deformation under 200 or $300 \mathrm{MPa}$ restricted the MT. Because the recovery strains of the three conditions were nearly the same in the range between 2 and $2.5 \%$, the work output plotted in Figure 9c was also nearly constant, regardless of the initial applied stress. A large work output was obtained in the sample with initial applied stresses of 200 and $300 \mathrm{MPa}$ because of the large recoverable strain, as shown in Figure 9b. Although some dispersion was observed due to dispersion of recoverable strain, the work output was very stable under all tested conditions after the second cycles. These results clarified that the initial applied stress affects the irrecoverable strain only for the first cycle.
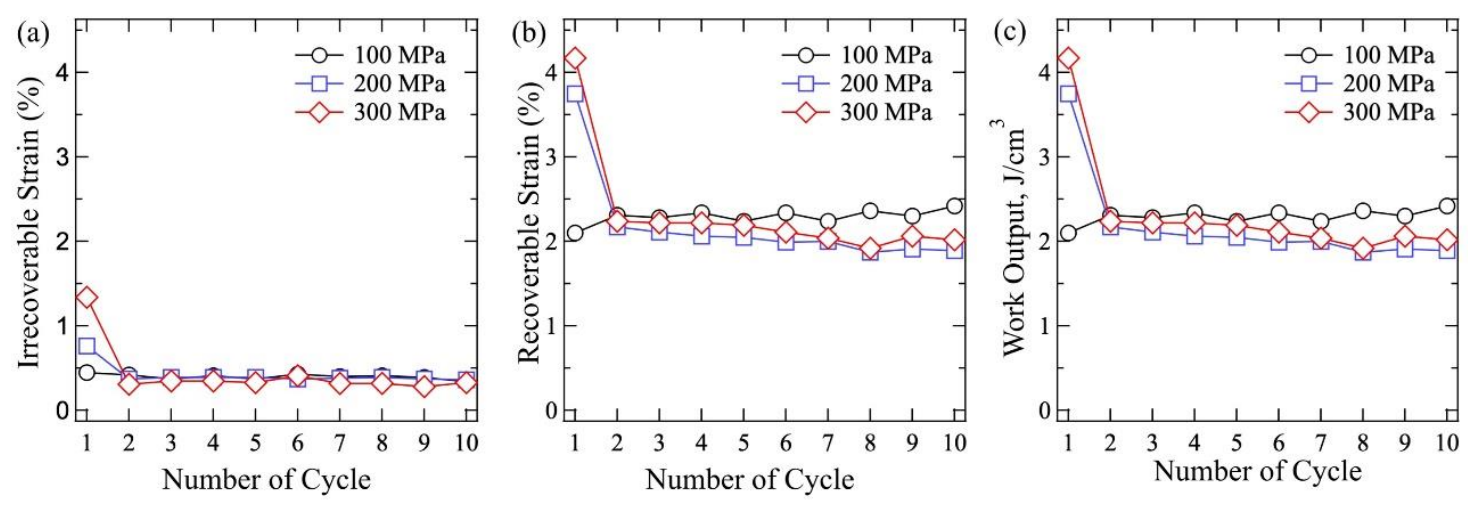

Figure 9. Irrecoverable strain, recoverable strain, and work output of Ti-35Pd-15Pt-5Zr at $100 \mathrm{MPa}$ after application of initial stress of (a) $100 \mathrm{MPa}$, (b) $200 \mathrm{MPa}$, and (c) $300 \mathrm{MPa}$. 
In the second test, the thermal cycle tests at different stresses of 200 and 300 MPa were performed eight times. The strain-temperature curves are shown in Figure 10. The large irrecoverable strain was obtained in the first curve under $200 \mathrm{MPa}$, but it decreased in the following cycles (Figure 10a). Still, an irrecoverable strain of approximately $1 \%$ appeared and was stable during the seven cycles. Under $300 \mathrm{MPa}$, trumpet-shaped curves were obtained (Figure 10b). A trumpet-shaped curve appears when the compressive deformation by the applied stress is greater than expansion by heating. It can then be said that compressive deformation progressed during heating, particularly at a temperature close to $A_{\mathrm{f}}$. The irrecoverable strain then drastically decreased in the subsequent cycles.
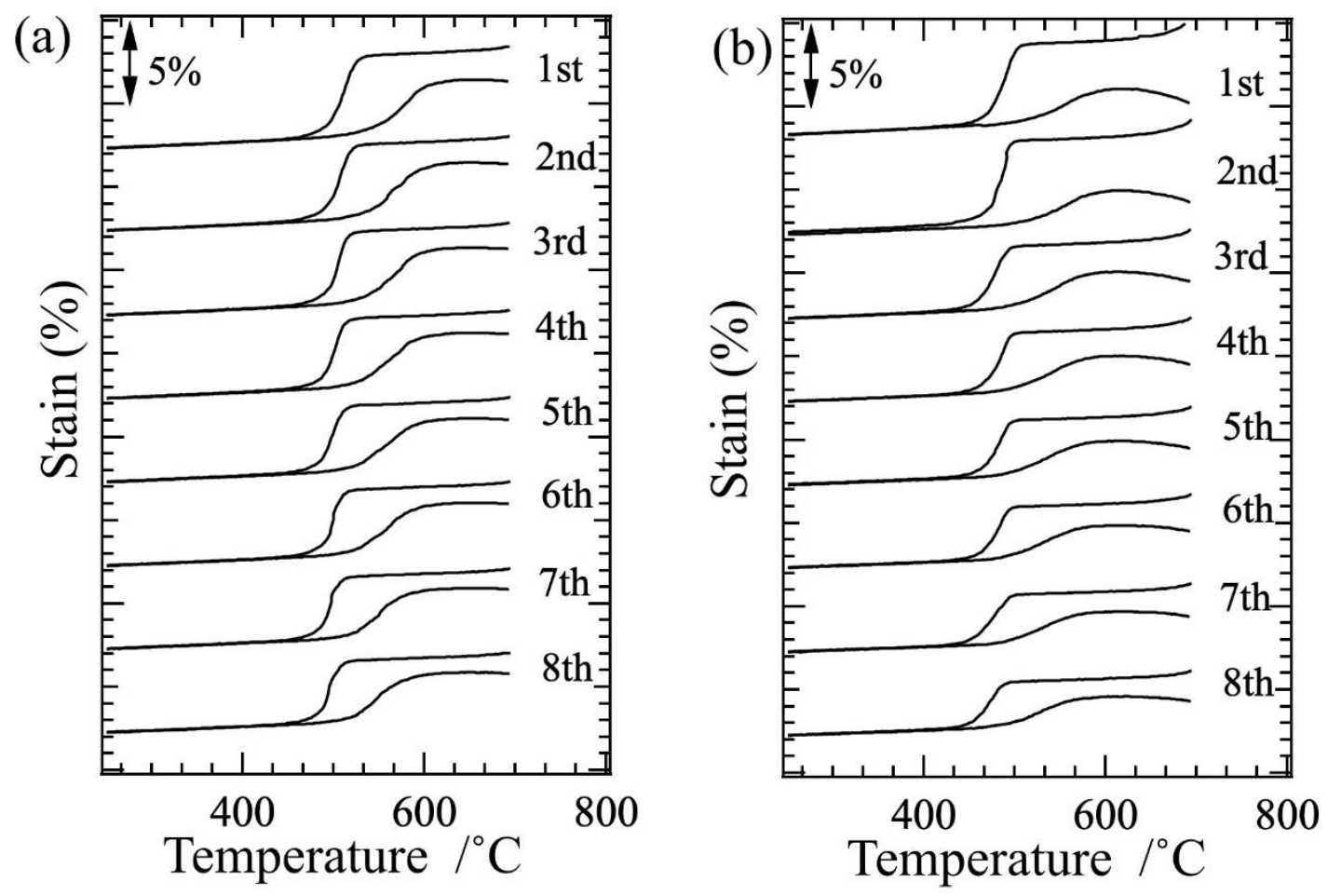

Figure 10. Thermal cycle test of Ti-35Pd-15Pt-5Zr under (a) $200 \mathrm{MPa}$ and (b) $300 \mathrm{MPa}$.

The irrecoverable and recoverable strains derived from Figure 10 are plotted against the number of cycles in Figure 11. The irrecoverable strain obtained at $100 \mathrm{MPa}$, as shown in Figure 9, was also plotted for comparison (see Figure 11a). Both the irrecoverable strain under $100 \mathrm{MPa}$ and recoverable strain were constant, that is, approximately $0.5 \%$ (Figure 11a) and approximately $2 \%$ (Figure 11b), respectively. This indicates that the training under $100 \mathrm{MPa}$ was too low to decrease the irrecoverable strain, and did not improve the shape memory effect. However, when the applied stresses were 200 and $300 \mathrm{MPa}$, the irrecoverable strain drastically decreased for the first five cycles and saturated at approximately 1\%, as shown in Figure 11a. The amount of decrease was greater under $300 \mathrm{MPa}$ than under $200 \mathrm{MPa}$, but the saturated irrecoverable strain was the same as that under $200 \mathrm{MPa}$ and double that under $100 \mathrm{MPa}$. The recoverable strain under $300 \mathrm{MPa}$ was smaller than that of $200 \mathrm{MPa}$, and became smaller with an increase in the number of cycles, as shown in Figure 11b. This indicates that the effect of decreasing irrecoverable strain is greater under a large applied stress, but the recoverable strain quickly decreases due to the large number of dislocations introduced during the first cycle. 

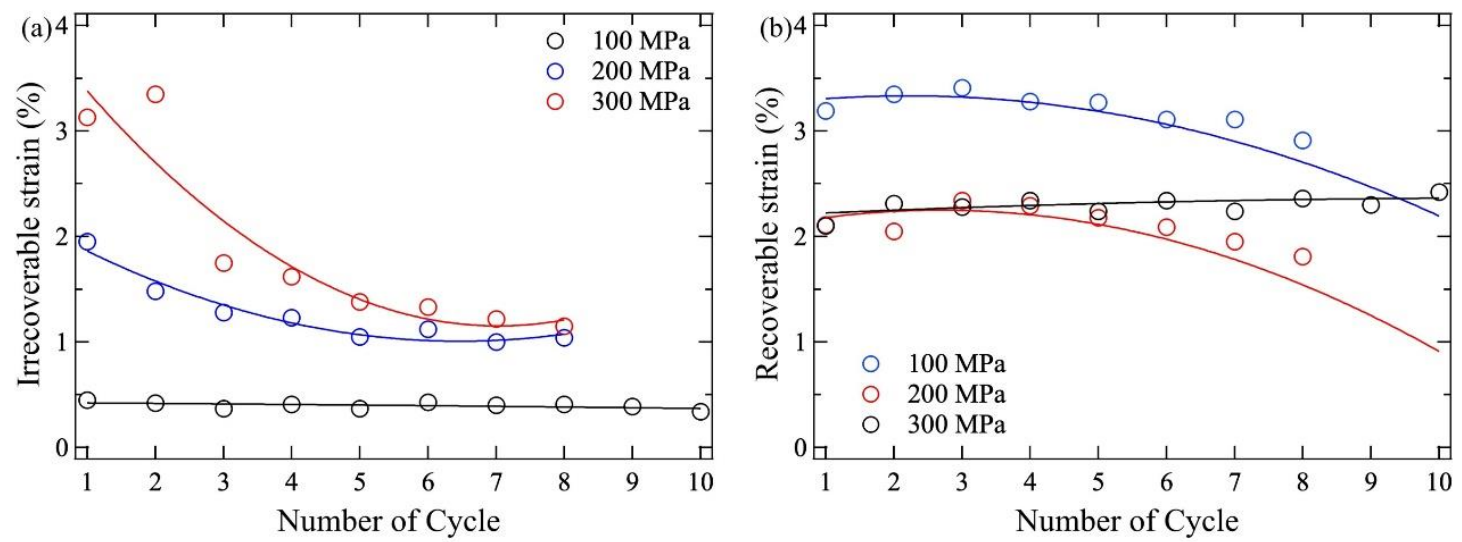

Figure 11. (a) Irrecoverable and (b) recoverable strains of Ti-35Pd-15Pt-5Zr during thermal cyclic testing under 100, 200, and $300 \mathrm{MPa}$.

To obtain small irrecoverable and stable recoverable strains, the thermal cyclic test under $100 \mathrm{MPa}$ is the best method under the different test conditions. Even so, the irrecoverable strain was not eliminated through the thermal cyclic test under $100 \mathrm{MPa}$.

In our previous study, similar behavior was observed in Ti-15Pd-35Pt-5Zr [29]. The thermal cyclic test was performed under $50 \mathrm{MPa}$ after initial applied stresses of 50, 100, and $200 \mathrm{MPa}$ were applied [29]. The recoverable strain decreased and was saturated after five cycles, but the irrecoverable strain was not perfectly eliminated. The work output then decreased during the cyclic test.

Although training was effective at decreasing and/or eliminating the irrecoverable strain for Ti-Ni alloys [32,33], it was not effective at eliminating the irrecoverable strain in Ti-Pd-Pt-Zr. This is because the strength of the austenite phase is less in Ti-Pd-Pt-Zr, due to a higher MTT than in Ti-Ni.

\subsection{Change in Microstructure Before and After Training}

The microstructures of the samples heat-treated at $1000{ }^{\circ} \mathrm{C}$ for $3 \mathrm{~h}$ followed by quenching in iced water, and tested samples by thermal cycling at 15, 50, 100, 150, and $200 \mathrm{MPa}$, were observed by SEM equipped with EBSD to investigate microstructural changes during training. The plane normal to the direction of compression was observed for the tested sample. Inverse pole figures of the corresponding microstructures are shown at the right of each orientation map in Figure 12a,b, respectively. A typical twin structure with multiple variants was observed in the heat-treated sample, as shown in Figure 12a. However, in the tested sample, the major variant was predominantly the [010] axis parallel to the compression axis, although a few minor variants were present with the different orientation, as shown in Figure 12b.

A similar texture was observed in Ti-Ni with a B19' structure after an in situ measurement was performed by synchrotron radiation facility [34,35]. Although Ti-Ni was thermally cycled 20 times at stresses of 50 to $150 \mathrm{MPa}$, the texture along the $[020]_{\mathrm{B} 19}$ was produced in a direction close to the tensile direction [35]. It is suggested that a martensite variant be selected to obtain the largest expansion of the lattice, and thus provide the greatest accommodation to the applied strain during the tensile test. In the Ti-Ni crystal, the lattice parameters of $a, b$, and c were $0.29,0.465$, and $0.432 \mathrm{~nm}$, respectively. Although the lattice parameter of the austenite phase was $0.302 \mathrm{~nm}$, the largest lattice change during phase transformation was obtained along the [020] direction. This supports the observation that the alignment of the martensite variant in the [020] direction occurs to accommodate the applied strain. 
(a)
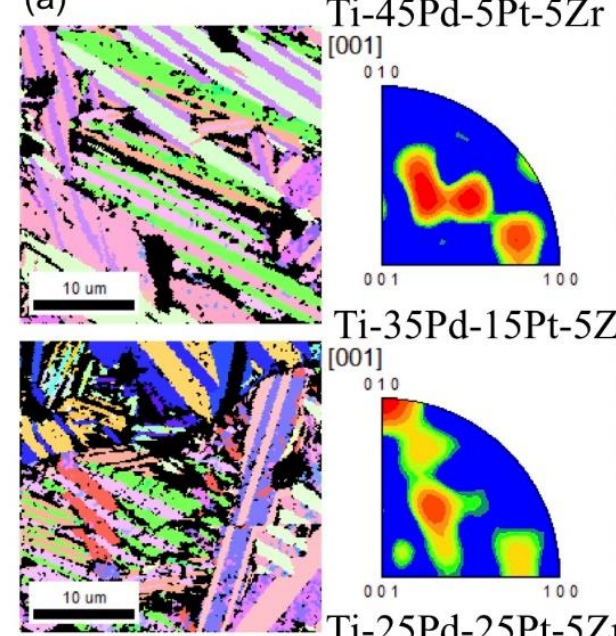

Ti-45Pd-5Pt-5Zr

[001]

[001]

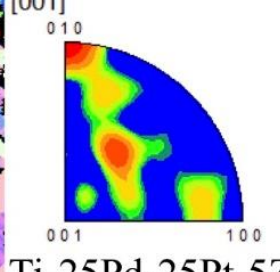

Ti-25Pd-25Pt-5Z

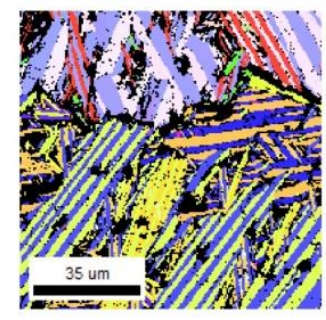

[001]

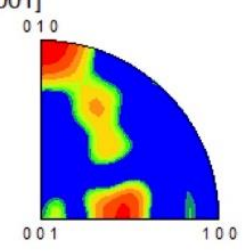

(b)
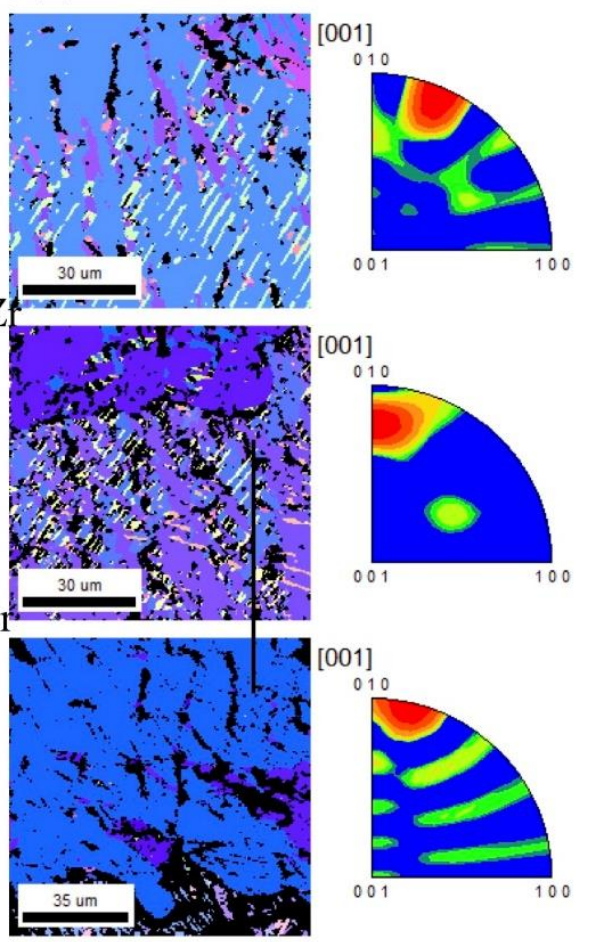

001]

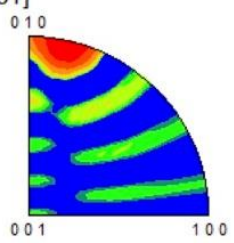

010

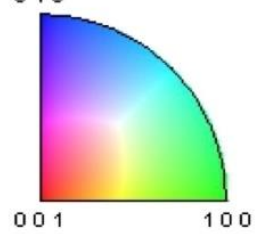

Figure 12. Orientation maps (left) and their inverse pole figures (right) of (a) heat-treated and (b) tested samples of Ti-35Pd-15Pt-5Zr. The perpendicular plane for the compression direction was observed in the tested sample.

In Ti-Pd, the lattice parameters of the orthorhombic B19 structure were $\mathrm{a}=0.459, \mathrm{~b}=0.28$, and $c=0.484 \mathrm{~nm}$ [36]. In the compression test, the martensite variant was selected to obtain the largest compression strain. The lattice parameter of $b$ was the smallest, that is, approximately $60 \%$ of the other two axes, and reorientation of the martensite variant along the [010] direction is therefore considered to relax the compressive strain under compressive stress. As a result, a greater recovery strain by deformed strain and reverse transformation was obtained after several thermal cycle tests, as compared with the single cycle test shown in Figure 6.

Similar behavior was also observed in Ti-50Pd- $(7,10) \mathrm{Zr}$ and Ti-50Pd-Zr-V [37]. The lattice parameter $\mathrm{b}$ remained the smallest, even after adding $\mathrm{Zr}$ or V. The transformation strain was calculated using the orientation relationship between martensite and austenite. The maximum compressive strain during MT was obtained along the [010] direction, whereas the maximum expansion strain was obtained during reverse transformation. This calculation indicates that the maximum recovery strain was obtained when the compression axis was parallel to the [010] direction. It was also found that perfect recovery was obtained in the alloy with a strong texture to the [010], whereas imperfect recovery was obtained in the alloy with a weak texture to the [010].

The lattice parameters of the martensite in the studied alloys, obtained from XRD patterns as presented in Figure 1, are shown in Table 4. Changes to lattice parameters were small with the additions of $\mathrm{Zr}$ and $\mathrm{Pt}$, and the smallest lattice parameter was obtained in [010]. The martensite variants changed close to [010] to obtain the largest transformation strain during MT. 
Table 4. Lattice parameters of the martensite phase at room temperature $(\AA)$.

\begin{tabular}{cccc}
\hline Alloys & a & b & c \\
\hline Ti-45Pd-5Pt-5Zr & 4.56 & 2.85 & 4.83 \\
Ti-35Pd-15Pt-5Zr & 4.6 & 2.83 & 4.85 \\
Ti-25Pd-25Pt-5Zr & 4.59 & 2.82 & 4.84 \\
\hline
\end{tabular}

\section{Conclusions}

In this study, the effects of Pt on MTT and shape recovery in Ti-50Pd-5Zr were investigated. Ti-(50-x) Pd-xPt-5Zr alloys $(x=5,15,25$ at $\%)$ were prepared. The MTT increased with an increase in Pt contents. For example, $A_{\mathrm{f}}$ increased from $511^{\circ} \mathrm{C}$ for Ti-50Pd-5Zr to $648{ }^{\circ} \mathrm{C}$ for Ti-25Pd-25Pt-5Zr. The shape recovery was investigated by thermal cyclic testing. Partial shape recovery was obtained under all test conditions, although irrecoverable strain also appeared. Pt addition decreased the recovery strain. The work output subsequently also decreased with increasing Pt content. To decrease the irrecoverable strain, the repeated thermal cyclic test, which is called training, was performed. The irrecoverable strain decreased as a result of this training, but it was not perfectly eliminated.

A microstructure orientation map indicated reorientation of the martensite variant in the direction of the small lattice axis (i.e., the [010] direction) during training. This was because the texture along [010] was effective in obtaining a large compressive strain.

Author Contributions: Conceptualization, Y.Y.-M.; Data curation, W.T.; Writing-original draft, W.T.; Writing-review and editing, Y.Y.-M.; Supervision, M.S. and Y.Y.-M.

Funding: This research was funded by Precious Metals Research Grant of TANAKA Memorial Foundation.

Acknowledgments: Authors appreciate technical support by Wataru Takebe.

Conflicts of Interest: The authors declare no conflict of interest. The funders had no role in the design of the study; in the collection, analyses, or interpretation of data; in the writing of the manuscript, or in the decision to publish the results.

\section{References}

1. Effects of Palladium Content, Quaternary Alloying, and Thermomechanical Processing on the Behavior of Ni-Ti-Pd Shape Memory Alloys for Actuator Applications. Available online: https://ntrs.nasa.gov/search.jsp? $\mathrm{R}=20080034881$ (accessed on 13 November 2019).

2. Ma, J.; Karaman, I.; Noebe, R.D. High temperature shape memory alloys. Int. Mater. Review 2010, 55, $257-315$. [CrossRef]

3. Bastin, G.F.; Rieck, G.D. Diffusion in the titanium-nickel system: I. occurrence and growth of the various intermetallic compounds. Metall. Trans. 1974, 5, 1817-1826. [CrossRef]

4. Yang, F.; Coughlin, D.R.; Phillips, P.J.; Yang, L.; Devaraj, A.; Kovarik, L. Structure analysis of a precipitate phase in an Ni-rich high-temperature NiTiHf shape memory alloy. Acta Mater. 2013, 9, 3335-3346. [CrossRef]

5. Santamarta, R.; Arroyave, R.; Pons, J.; Evrigen, A.; Karaman, I.; Karacka, H.E.; Noebe, R.D. TEM study of structural and microstructural characteristics of a precipitate phase in Ni-rich Ni-Ti-Hf and Ni-Ti-Zr shape memory alloys. Acta Mater. 2013, 61, 6191-6206. [CrossRef]

6. Bigelow, G.S.; Garg, A.; Padula, S.A., II; Gaydosh, D.J.; Noebe, R.D. Load-biased shape-memory and superelastic properties of a precipitation strengthened high-temperature $\mathrm{Ni}_{50.3} \mathrm{Ti}_{29.7} \mathrm{Hf}_{20}$ alloy. Scripta Mater. 2011, 64, 725-728. [CrossRef]

7. Coughlin, D.R.; Phillips, P.J.; Bigelow, G.S.; Garg, A.; Noebe, R.D.; Mills, M.J. Characterization of the microstructure and mechanical properties of a 50.3Ni-29.7Ti-20Hf shape memory alloy. Scripta Mater. 2012, 67, 112-115. [CrossRef]

8. Benafan, O.; Noebe, R.D.; Padula, S.A., II; Vaidyanathan, R. Microstructural Response During Isothermal and Isobaric Loading of a Precipitation-Strengthened Ni-29.7Ti-20Hf High-Temperature Shape Memory Alloy. Metall. Mater. Trans. A 2012, 43, 4539-4552. [CrossRef] 
9. Karaca, H.E.; Saghaian, S.M.; Ged, G.; Tobe, H.; Basaran, B.; Maier, H.J.; Noebe, R.D.; Chumlyakov, Y.I. Effects of nanoprecipitation on the shape memory and material properties of an Ni-rich NiTiHf high temperature shape memory alloy. Acta Mater. 2013, 61, 7422-7431. [CrossRef]

10. Benafan, O.; Grag, A.; Noebe, R.D.; Bigelow, G.S.; Padula, S.A., II; Gaydosh, D.J.; Schell, N.; Mabe, J.H.; Vaidyanathan, R. Mechanical and functional behavior of a Ni-rich $\mathrm{Ni}_{50.3} \mathrm{Ti}_{29.7} \mathrm{Hf}_{20}$ high temperature shape memory alloy. Intermetallics 2014, 50, 94-107. [CrossRef]

11. Pio, J.S.B.; Hee, Y.K.; Hideki, H.; Shuichi, M. Shape memory behavior of Ti-Ta and its potential as a high-temperature shape memory alloy. Acta Mater. 2009, 57, 1068-1077. [CrossRef]

12. Joanne, L.M. The Pd-Ti (Palladium-titanium) system. Bull. Alloy Phase Diagr. 1982, 3, 321-329.

13. Donkersloot, H.C.; Van Vucht, J.H.N. Martensitic transformations in gold-titanium, palladium-titanium and platinum-titanium alloys near the equiatomic composition. J. Less Common Metals 1970, 20, 83-91. [CrossRef]

14. Otsuka, K.; Oda, K.; Ueno, Y.; Piao, M.; Ueki, T.; Horikawa, H. The shape memory effect in a Ti\{sub 50\}Pd\{sub 50\} alloy. Scripta Met. Mater. 1993, 29, 1355-1358. [CrossRef]

15. Yamabe-Mitarai, Y.; Hara, T.; Miura, S.; Hosoda, H. Potentials of Shape Memory Effect in (Pt, Ir)-50 at\%Ti. J. Jpn. Inst. Metals 2005, 69, 634-642. [CrossRef]

16. Yamabe-Mitarai, Y.; Hara, T.; Miura, S.; Hosoda, H. Mechanical Properties of Ti-50(Pt,Ir) High-Temperature Shape Memory Alloys. Mater. Trans. 2006, 47, 650-657. [CrossRef]

17. Kawakita, M.; Takahashi, M.; Takahashi, S.; Yamabe-Mitarai, Y. Effect of Zr on phase transformation and high-temperature shape memory effect in TiPd alloys. Mater Lett. 2012, 89, 336-338. [CrossRef]

18. Arockiakumar, R.; Takahashi, M.; Takahashi, S.; Yamabe-Mitarai, Y. Microstructure, mechanical and shape memory properties of Ti-55Pd-5x (x=Zr, Hf, V, Nb) alloys. Mat. Sci. Eng. A 2013, 585, 85-93. [CrossRef]

19. Wadood, A.; Hosoda, H.; Yamabe-Mitarai, Y. Phase transformation, oxidation and shape memory properties of Ti-50Au-10Zr alloy for high temperature applications. J. Alloy Comp. 2014, 595, 200-205. [CrossRef]

20. Wadood, A.; Yamabe-Mitarai, Y. Silver- and Zirconium-added ternary and quaternary TiAu based high temperature shape memory alloys. J. Alloy Comp. 2015, 646, 1172-1177. [CrossRef]

21. Yamabe-Mitarai, Y.; Hara, T.; Miura, S.; Hosoda, H. Shape memory effect and pseudoelasticity of TiPt. Intermetallics 2010, 18, 2275-2280. [CrossRef]

22. Yamabe-Mitarai, Y.; Hara, T.; Miura, S.; Hosoda, H. Phase Transformation and Shape Memory Effect of Ti (Pt, Ir). Metall. Mater. Trans. A 2012, 43, 2901-2911. [CrossRef]

23. Yamabe-Mitarai, Y.; Hara, T.; Kitashima, T.; Miura, T.; Hosoda, H. Composition dependence of phase transformation behavior and shape memory effect of Ti (Pt, Ir). J. Alloy Compd. 2013, 577, S399-S403. [CrossRef]

24. Wadood, A.; Takahashi, M.; Takahashi, S.; Hosoda, H.; Yamabe-Mitarai, Y. High-temperature mechanical and shape memory properties of TiPt-Zr and TiPt-Ru alloys. Mater. Sci. Eng. A 2013, 564, 34-41. [CrossRef]

25. Wadood, A.; Yamabe-Mitarai, Y. TiPt-Co and TiPt-Ru high temperature shape memory alloys. Mater. Sci. Eng. A 2014, 610, 106-110. [CrossRef]

26. Yamabe-Mitarai, Y.; Wadood, A.; Arockiakumar, R.; Takahashi, M.; Takahashi, S.; Hosoda, H. High-temperature shape memory alloys based on Ti-platinum group metals compounds. Mater. Sci. Forum 2014, 783, 2541-2545. [CrossRef]

27. Yamabe-Mitarai, Y.; Arockiakumar, R.; Wadood, A.; Suresh, K.S.; Kitashima, T.; Hara, T.; Shimojo, M.; Tasaki, W.; Takahashi, M.; Takahashi, S.; et al. Ti (Pt, Pd, Au) based high temperature shape memory alloys. Mater. Today: Proc. 2015, 2, S517-S522. [CrossRef]

28. Yamabe-Mitarai, Y. Development of High-Temperature Shape Memory Alloys above 673 K. Mater. Sci. Forum. 2017, 879, 107-112. [CrossRef]

29. Yamabe-Mitarai, Y.; Takebe, W.; Shimojo, M. Phase Transformation and Shape Memory Effect of Ti-Pd-Pt-Zr High-Temperature Shape Memory Alloys. Shape Mem. Superelasticity 2017, 3, 381-391. [CrossRef]

30. Takei, F.; Miura, T.; Miyazaki, S.; Kimura, S.; Otsuka, K.; Suzuki, Y. Stress-induced martensitic transformation in a Ti-Ni single crystal. Scripta Metall. 1983, 17, 987-992. [CrossRef]

31. Senkov, O.N.; Miracle, D.B. Effect of the atomic size distribution on glass forming ability of amorphous metallic alloys. Mater. Res. Bull. 2001, 36, 2183-2198. [CrossRef]

32. Atli, K.C.; Karaman, I.; Noebe, R.D.; Maier, H.J. Comparative analysis of the effects of severe plastic deformation and thermomechanical training on the functional stability of $\mathrm{Ti}_{50.5} \mathrm{Ni}_{24.5} \mathrm{Pd}_{25}$ high-temperature shape memory alloy. Scr. Mater. 2011, 64, 315-318. [CrossRef] 
33. Atli, K.C.; Franco, B.E.; Karaman, I.; Gaydosh, D.; Noebe, R.D. Influence of crystallographic compatibility on residual strain of TiNi based shape memory alloys during thermo-mechanical cycling. Mater. Sci. Eng. A 2013, 574, 9-16. [CrossRef]

34. Hasen, M.; Schmahl, W.W.; Hackl, K.; Heinen, R.; Frenzel, J.; Gollerthan, S.; Eggeler, G.; Wagner, M.; Khalil-Allafi, J.; Baruj, A. Hard X-ray studies of stress-induced phase transformations of superelastic NiTi shape memory alloys under uniaxial load. Mat. Sci. Eng. A 2008, 481-482, 414-419. [CrossRef]

35. Jones, N.G.; Dye, D. Martensite evolution in a NiTi shape memory alloy when thermal cycling under an applied load. Intermetallics 2011, 19, 1348-1358. [CrossRef]

36. Villars, P.; Cenzual, K. (Eds.) Pearson's Crystal Data-Crystal Structure Database for Inorganic Compounds; ASM International $(\mathrm{OH})$ : Novelty, OH, USA, 2010.

37. Sato, H.; Kim, Y.H.; Shimojo, M.; Yamabe-Mitarai, Y. Training Effect on Microstructure and Shape Recovery in Ti-Pd-Zr Alloys. Mater. Trans. 2017, 58, 1479-1486. [CrossRef]

(C) 2019 by the authors. Licensee MDPI, Basel, Switzerland. This article is an open access article distributed under the terms and conditions of the Creative Commons Attribution (CC BY) license (http://creativecommons.org/licenses/by/4.0/). 